\title{
Regulation of E2Fs and senescence by PML nuclear bodies
}

\author{
Mathieu Vernier, ${ }^{1,3}$ Véronique Bourdeau, ${ }^{1,3}$ Marie-France Gaumont-Leclerc, ${ }^{1}$ Olga Moiseeva, ${ }^{1}$ \\ Virginie Bégin, ${ }^{1}$ Fred Saad, ${ }^{2}$ Anne-Marie Mes-Masson, ${ }^{2}$ and Gerardo Ferbeyre ${ }^{1,4}$ \\ ${ }^{1}$ Biochemistry Department, Université de Montréal, Montréal, Québec H3C3J7, Canada; ${ }^{2}$ Centre Hospitalier de 1'Université de \\ Montréal (CHUM), Université de Montréal, Montréal, Québec H1L4M1, Canada
}

\begin{abstract}
The tumor suppressor PML (promyelocytic leukemia protein) regulates cellular senescence and terminal differentiation, two processes that implicate a permanent exit from the cell cycle. Here, we show that the mechanism by which PML induces a permanent cell cycle exit and activates p53 and senescence involves a recruitment of E2F transcription factors bound to their promoters and the retinoblastoma (Rb) proteins to PML nuclear bodies enriched in heterochromatin proteins and protein phosphatase $1 \alpha$. Blocking the functions of the $R b$ protein family or adding back E2Fs to PML-expressing cells can rescue their defects in E2F-dependent gene expression and cell proliferation, inhibiting the senescent phenotype. In benign prostatic hyperplasia, a neoplastic disease that displays features of senescence, PML was found to be up-regulated and forming nuclear bodies. In contrast, PML bodies were rarely visualized in prostate cancers. The newly defined PML/Rb/E2F pathway may help to distinguish benign tumors from cancers, and suggest E2F target genes as potential targets to induce senescence in human tumors.
\end{abstract}

[Keywords: E2F; senescence; retinoblastoma; PML; prostate tumors]

Supplemental material is available for this article.

Received July 27, 2010; revised version accepted November 16, 2010.

PML (promyelocytic leukemia protein) was discovered as a gene target for translocations with the retinoic acid receptor gene in acute promyelocytic leukemia (Kakizuka et al. 1991). The expression of PML in primary cells leads to a permanent cell cycle arrest similar to the one triggered by short telomeres or oncogenes and known as cellular senescence (Ferbeyre et al. 2000; Pearson et al. 2000; Bischof et al. 2002). Senescence is an effective anticancer mechanism in vivo (Braig et al. 2005; Chen et al. 2005; Michaloglou et al. 2005), and PML has been shown to be important for the senescent response to oncogenic ras (Ferbeyre et al. 2000; Pearson et al. 2000; de Stanchina et al. 2004). PML also plays a role in the regulation of cell differentiation (Li et al. 2009; Regad et al. 2009), a process that often involves a terminal cell cycle arrest. PML expression is often lost in human cancers /Gurrieri et al. 2004), while mice with genetic inactivation of PML are tumor-prone (Wang et al. 1998).

The mechanism by which PML contributes to senescence involves the retinoblastoma $(\mathrm{Rb})$ and the $\mathrm{p} 53$ tumor suppressors (Ferbeyre et al. 2000; Pearson et al. 2000; Bischof et al. 2002; de Stanchina et al. 2004), two proteins

\footnotetext{
${ }^{3}$ These authors contributed equally to this work.

${ }^{4}$ Corresponding author.

E-MAIL g.ferbeyre@umontreal.ca; FAX (514) 343-2210.

Article is online at http://www.genesdev.org/cgi/doi/10.1101/gad.1975111.
}

that can interact directly with PML (Alcalay et al. 1998; Fogal et al. 2000). PML is capable of inducing cell cycle arrest and senescence in cells with inactivated p53, but not in cells where the $\mathrm{Rb}$ family of pocket proteins $(\mathrm{Rb}$, p107, and p130) is disrupted by the E7 oncoprotein from papillomavirus (Mallette et al. 2004). The $\mathrm{Rb}$ pathway controls the cell cycle at the transcriptional level via repression of E2F target genes (Dyson 1998; Muller et al. 2001; Chicas et al. 2010). However, the retinoblastomamediated E2F repression can be observed both in a reversible cell cycle arrest and during the permanent cell cycle arrest associated with senescence and cell differentiation. Since high levels of PML expression characterize senescence but not a reversible cell cycle arrest (Ferbeyre et al. 2000; Bourdeau et al. 2009), it is plausible that PML has a specific impact on the way E2F target genes are regulated.

Here we describe a mechanism by which PML controls the activity of the E2F transcription factors. We show that $\mathrm{Rb} / \mathrm{E} 2 \mathrm{~F}$ complexes were relocalized into PML nuclear bodies along with heterochromatin proteins when inducing senescence by the expression of oncogenic ras or the tumor suppressor PML. PML overexpression was sufficient to inhibit E2F target gene expression, block cell proliferation, and induce DNA damage and senescence. Adding back E2Fs to PML-expressing cells could rescue their proliferation defect and senescent phenotype. The 
Vernier et al.

localization of E2Fs into PML bodies was found to be dependent on the $\mathrm{Rb}$ protein family. The clinical relevance of this mechanism was investigated in prostate tumors. While benign prostate tumors displayed abundant PML bodies, they were rare in prostate cancers.

\section{Results}

\section{PML represses E2F target gene expression}

To investigate the effects of PML on E2F target gene expression, we introduced PML-IV (referred to as PML hereafter) into the human diploid fibroblast IMR90. PMLexpressing fibroblasts arrested their proliferation rapidly after selection (Supplemental Fig. S1A) and developed characteristics of cellular senescence, including a flat morphology, positive staining for the senescence-associated $\beta$-galactosidase (SA- $\beta$-Gal) (Supplemental Fig. S1B), expression of high levels of IL-8 (a cytokine highly expressed by senescent cells) (Supplemental Fig. S1C; Acosta et al. 2008), and markers of mitochondrial dysfunction and biogenesis (Supplemental Fig. S1D-F), which also characterize senescence (Passos et al. 2007; Moiseeva et al. 2009).

Next we measured the expression of several E2F target genes in cells expressing PML at a time before senescence markers were detected. Several E2F target genes that play a role in DNA replication, cell cycle progression, and DNA repair were found to be down-regulated in normal fibroblasts expressing PML (Fig. 1A). To have an unbiased representation of the E2F targets repressed by PML, we performed a microarray analysis of cells expressing PML or a vector control. The down-regulated genes were then analyzed by two algorithms that search for transcription factor-binding sites for any set of input genes: TFactS (Essaghir et al. 2010) and DIRE (Gotea and Ovcharenko 2008). Genes with E2F-binding sites were enriched in the data set (Fig. 1B; Supplemental Table 1) and an analysis of their known functions indicates that PML represses genes involved in DNA replication, repair, and checkpoints (Supplemental Tables 2,3). We also analyzed the down-regulated genes in PML-senescence and compared the data with the set of genes that bind E2F according to data combining chromatin immunoprecipitation (ChIP)

A

Cell Cycle Targets
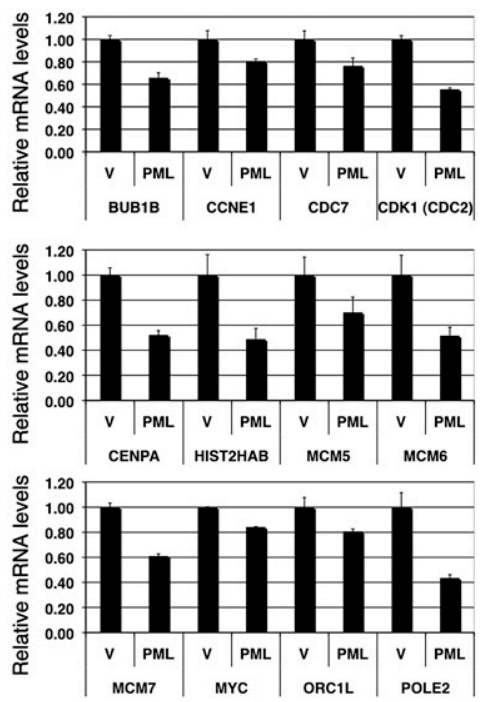

B.

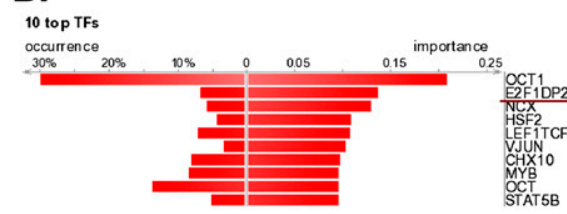

D.

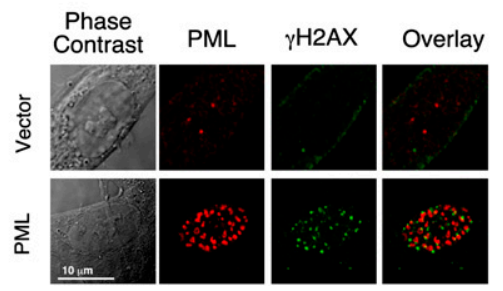

DNA Repair Targets
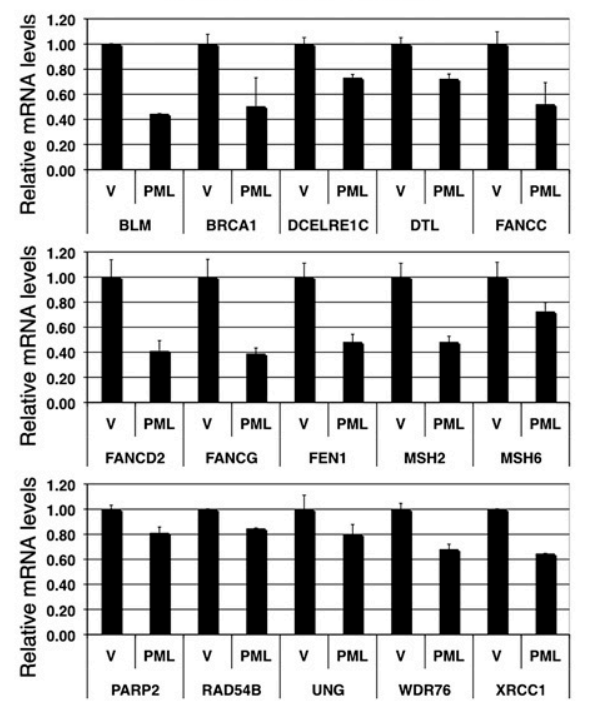

C.

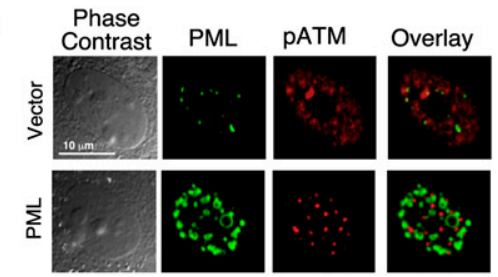

E.

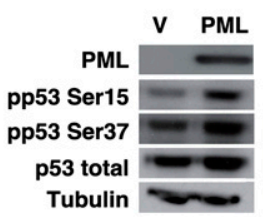

F.

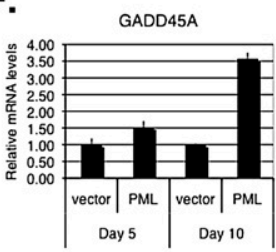

Figure 1. PML represses E2F target genes and induces p53 and the DNA damage response. (A) qPCR for selected cell cycle genes and DNA repair genes. Total RNA was extracted from IMR90 fibroblasts five days after infection with a PML-IV-expressing retrovirus when cells were not yet senescent according to the SA- $\beta$-Gal marker (Supplemental Fig. S1B). (B) DIRE analysis of genes found to be down-regulated in PMLexpressing cells using Affymetrix microarrays (Génome Québec). (C) PML and phospho-ATM $^{\text {S1981 }}$ (pATM) foci in IMR90 cells expressing PML or a vector control fixed $9 \mathrm{~d}$ post-infection, as revealed by indirect immunofluorescence staining with specific anti-PML and anti-phospho-ATM ${ }^{\text {S1981 }}$ antibodies followed by confocal microscopy. (D) PML and $\gamma \mathrm{H} 2 \mathrm{AX}$ foci in cells as in $C$. (E) Immunoblots for the indicated proteins in cells expressing PML or a vector control in cells as in $C$. $(F)$ qPCR for the p53 target gene GADD45A using RNA from cells at days 5 and 10 post-infection. 
and microarray analysis (ChIP-chip) (Xu et al. 2007). E2F targets were enriched sixfold among PML down-regulated genes in comparison with a random set of genes (Supplemental Tables 4, 5).

The decrease in the expression of genes required for DNA repair and checkpoints promptly after PML expression suggests a mechanism by which PML could contribute to the senescence cell cycle arrest, which we know involves DNA damage signals (Bartkova et al. 2006; Di Micco et al. 2006; Mallette et al. 2007). In agreement with this, cells disabled for certain DNA repair genes senesce in culture due to their inability to repair the DNA damage triggered by endogenous metabolic processes (Cao et al. 2003; Neri et al. 2007; Zhang et al. 2007; Chang et al. 2008). Consistent with this idea, PML-expressing cells contained DNA damage foci labeled by anti-phosphoATM (Fig. 1C) and anti- $\gamma \mathrm{H} 2 \mathrm{AX}$ (Fig. 1D) antibodies. We also found that p53 was phosphorylated at the ATM/ATR sites (Ser 15 and Ser 37) (Tibbetts et al. 1999; Armata et al. 2007) 9 d after PML expression (Fig. 1E), and that the p53dependant gene GADD $45 \alpha$ was significantly up-regulated $10 \mathrm{~d}$ after PML expression but not at an earlier time point (Fig. 1F). Taken together, our results reveal that the down-regulation of E2F target gene expression in PMLexpressing cells precedes the activation of p53, the DNA damage response, and the senescence phenotype.

\section{PML induces localization of E2F1-3 into PML nuclear bodies}

Next, we used immunostaining and confocal microscopy of E2F-1, E2F-2, and E2F-3 in cells expressing PML at a time point where the cells did not yet display senescent markers (day 5 post-infection). We found that E2F1 and E2F3 were dramatically confined to PML bodies, while E2F2 was found both in the nucleoplasm and in PML bodies (Fig. 2A-C). We also studied E2F3 localization in cells where senescence was induced by serial passage (replicative senescence) or with $\beta$-interferon, and found that, in these conditions, E2F3 localized into endogenous PML bodies as well (Fig. 2D).

To investigate the temporal relationship between E2F localization to endogenous PML bodies and senescence, we induced the process of oncogene-induced senescence in normal fibroblasts, which is known to involve PML (Ferbeyre et al. 2000; Pearson et al. 2000; de Stanchina et al. 2004). For this experiment, we used an antibody specific for E2F3, which is the most abundant isoform among activator E2Fs (E2F1-3) in normal human fibroblasts (Supplemental Fig. S2A). We found few PML bodies in normal growing cells and a diffuse nuclear staining pattern of E2F3. Early after introduction of RasV12 (days 1 and 3 after infection), and before senescence markers can be detected, E2F3 localized to PML bodies. This phenotype was maintained at later times after introduction of RasV12, when senescence markers were readily expressed (Fig. 3; Supplemental Fig. S2B). It has been suggested that E2F target genes are permanently repressed during oncogene-induced senescence by formation of heterochromatin structures known as SAHF (senescence-associated het-

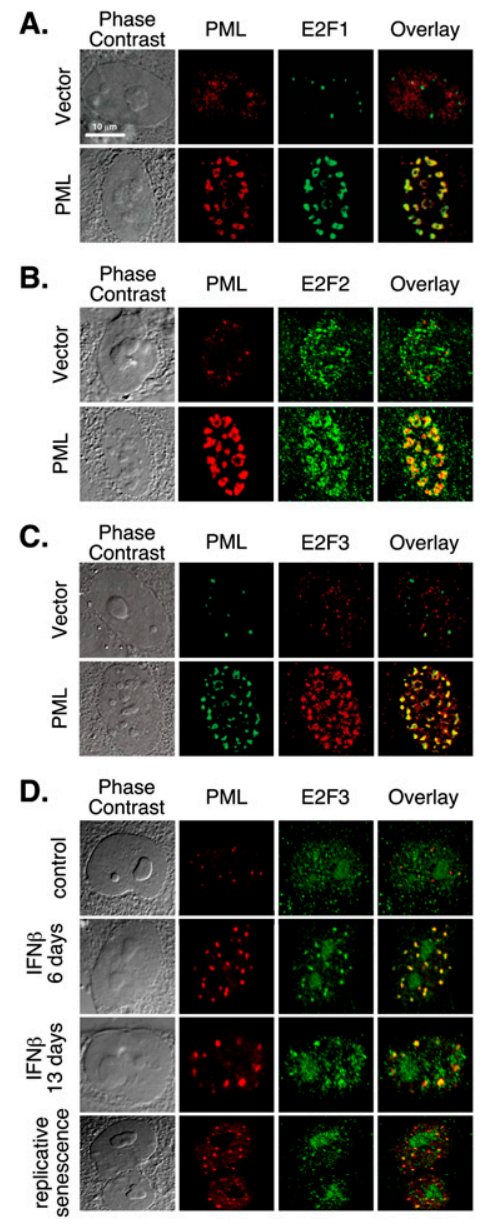

Figure 2. Association of E2F1-3 with PML bodies. $(A-D)$ Colocalization of PML with E2F1, E2F2, or E2F3 as revealed by indirect immunofluorescence staining with specific anti-PML and anti-E2F1-3 antibodies followed by laser-scanning confocal microscopy. $(A-C)$ IMR90 fibroblasts expressing PML $5 \mathrm{~d}$ postinfection. (D) IMR90 fibroblasts after treatment for 6 or $13 \mathrm{~d}$ with $2000 \mathrm{U}$ of $\beta$-interferon (INF $\beta$ ) or serially passed until they reached replicative senescence.

erochromatin foci) (Narita et al. 2003, 2006). PML bodies may play a role in SAHF formation because they recruit heterochromatin components early in the senescence process. These proteins are later found localized to the SAHF (Zhang et al. 2005; Ye et al. 2007). As reported before, we observed that the SAHF component HP1 $\gamma$ localizes to PML bodies early during the senescence process induced by oncongenic ras (Supplemental Fig. S2B,C), at about the same time that E2F3 is also visualized at PML bodies (Fig. 3). However, by the time SAHF are established, SAHF and PML bodies are two clearly distinguishable nuclear structures (Supplemental Fig. S3). This transient association of heterochromatin proteins with PML bodies intriguingly suggests that PML bodies are sites of nucleation for heterochromatin on E2F promoters, and that the resulting repression of E2F targets is the mechanism by which PML induces senescence. 


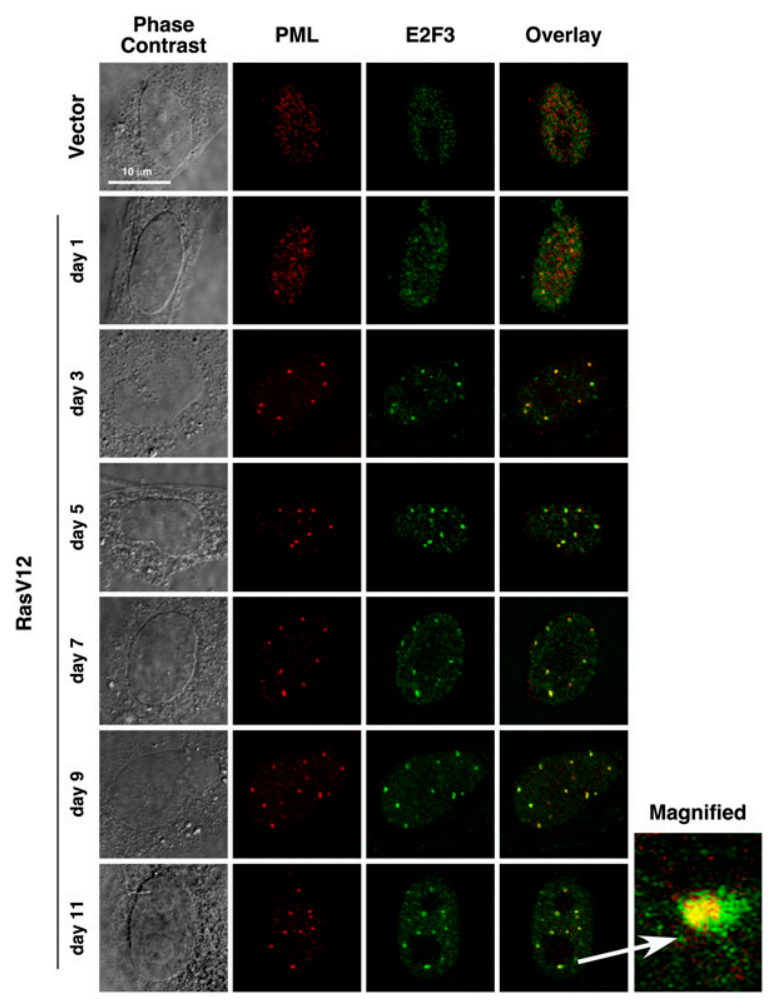

Figure 3. E2F3 localization in PML bodies in normal human fibroblasts after expression of oncogenic ras. Cells expressing oncogenic ras (RasV12) or an empty vector were fixed at the indicated times after retroviral infection and costained with anti-E2F3 and anti-PML antibodies. Signals were identified by confocal immunofluorescence after immunostaining with secondary antibodies. Images are representative of most cells in the populations. A magnified PML body is shown at the bottom right.

\section{Does PML-induced senescence depend} on E2F inhibition?

It is well established that E2F-dependent transcription is repressed in cells undergoing senescence by the tumor suppressors of the Rb family (Dimri et al. 1994; Rowland et al. 2002; Narita et al. 2003; Maehara et al. 2005; Chicas et al. 2010). However, the $\mathrm{Rb}$ family also represses the E2F transcription factors during quiescence and other forms of reversible cell cycle arrests (Smith et al. 1996). During senescence and terminal differentiation, the $\mathrm{Rb}$ protein localizes to PML bodies (Ferbeyre et al. 2000; Mallette et al. 2004; Regad et al. 2009), suggesting that PML bodies confer a unique environment for $\mathrm{Rb}$ functions relevant to senescence. $\mathrm{Rb}$ localization to PML bodies involves a direct interaction with the PML protein (Alcalay et al. 1998), indicating that, upon an increase in PML expression, $\mathrm{Rb}$ can be recruited to PML bodies. Since $\mathrm{Rb}$ binds E2Fs, the recruitment of the latter to PML bodies can be a consequence of their interaction with $\mathrm{Rb}$.

To investigate whether E2Fs localize to PML bodies via the Rb family, we used the oncoprotein E7 from papillomavirus, which can simultaneously block the function of the pocket proteins $\mathrm{Rb}, \mathrm{p} 107$, and $\mathrm{p} 130$. Introduction of
E7 caused a release of both $\mathrm{Rb}$ (Fig. 4A) and E2F1 (Fig. 4B) from the PML bodies without affecting the number of PML bodies or the expression of PML (Mallette et al. 2004). This is consistent with the fact that E7 completely bypassed PML-induced senescence (Mallette et al. 2004; Bischof et al. 2005). Next, we used E7 in-frame deletion mutants with different functionalities. E7 $\Delta 6-10$ is a deletion of the CR1 region of E7, while E7 $\Delta 21-24$ is a deletion in the LXCXE motif of the CR2 region of E7 responsible for binding $\mathrm{Rb}$. These two regions are both required for transformation by E7 and destabilization of $\mathrm{Rb}$ (Phelps et al. 1992). Consistent with the proposed role of $\mathrm{Rb}$ in the senescence functions of PML, E7 $\Delta 6-10$ or E7 $\Delta 21-24$ was not able to inhibit senescence (Fig. 4C), stimulate E2F gene expression (Fig. 4D), or inhibit E2F localization to PML bodies (Supplemental Fig. S4) like wild-type E7. In addition, the mutant E7 $\Delta 79-83$, which efficiently binds and destabilizes Rb (Helt and Galloway 2001), inhibited both senescence and E2F colocalization with PML bodies while it stimulated E2F target gene expression with an efficiency similar to wild-type E7 (Fig. 4C,D; Supplemental Fig. S4). Thus, the ability of E7 to rescue PML-induced senescence correlated with its ability to bind and destabilize $\mathrm{Rb}$. This also suggests that PML-induced senescence depends on E2F inhibition.

Next, we investigated whether increasing the levels of cellular E2F1-3 could block PML-induced senescence. First, we coinfected human diploid fibroblast IMR90 with plasmids expressing PML or E2F-1, E2F-2, or E2F-3 fused with the ligand-binding domain of the estrogen receptor (ER) (Vigo et al. 1999). After selection of the population expressing the two plasmids, we treated them with 100 $\mathrm{nM}$ 4-hydroxytamoxifen (OHT) for $48 \mathrm{~h}$ to induce E2F activity. We found that induction of E2F1-3 stimulated DNA synthesis (Fig. 4E) and inhibited PML-induced senescence (Fig. 4F). Deletion of the Rb-binding domain of E2F2 impaired its ability to increase DNA synthesis (Fig. 4E) or inhibit senescence after PML expression (Fig. 4E,F). Moreover, deletion of the Rb-binding domain of E2F2 prevented its localization into PML bodies (Supplemental Fig. S5). These results support the hypothesis that PML induces senescence by blocking E2F activity in association with $\mathrm{Rb}$ at PML bodies.

\section{PML inhibits E2F gene expression in tumor cells}

The ability of PML to induce senescence in normal human fibroblasts depends on genetic mechanisms that remain unaltered in these cells. It is important to find to what extent PML can engage the same pathway in tumor cells, and which are the factors present in these cells that may inhibit PML functions. We thus used U2OS osteosarcoma cells that possess wild-type p53 and Rb. Expression of PML-IV in U2OS cells inhibited cell growth (Supplemental Fig. S6A) and led to repression of E2F target genes (Supplemental Fig. S6B) and DNA damage foci (Supplemental Fig. S6C), which are characteristic of cellular senescence. However, these cells did not stain for SA- $\beta-$ Gal. Nevertheless, we found a similar localization of E2F3 and E2F1(Fig. 5A; Supplemental Fig. S6D) into 

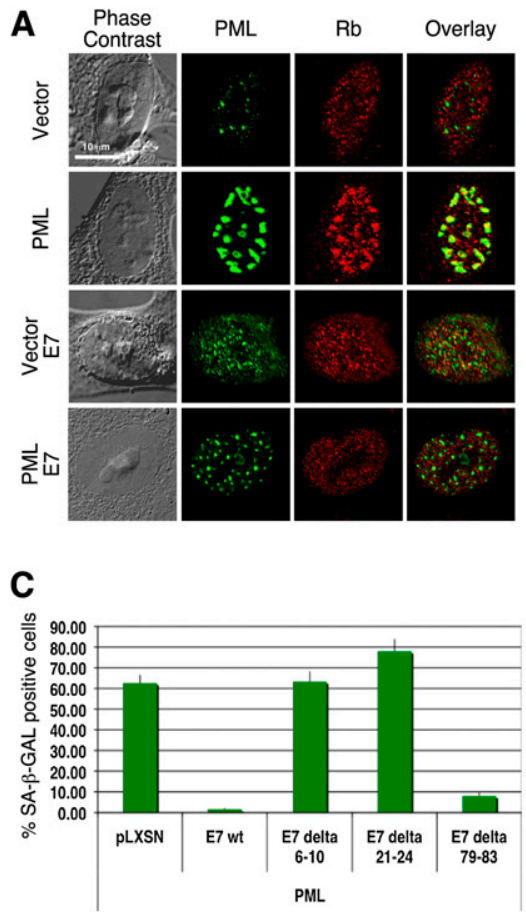

E

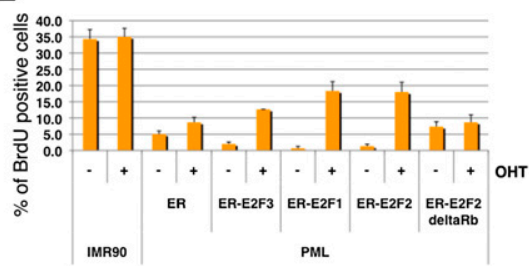

B

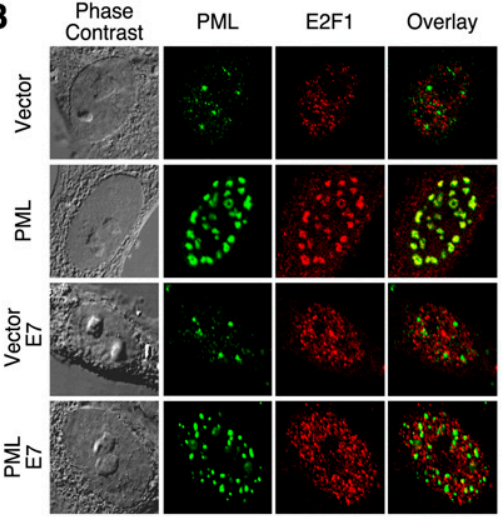

D

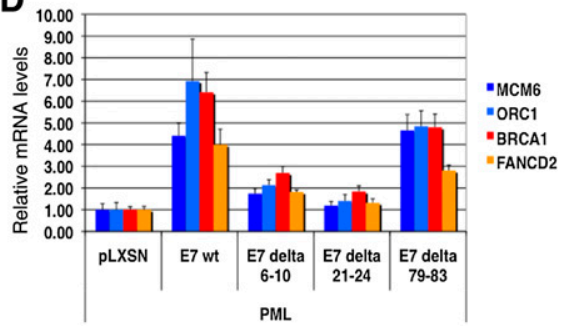

$\mathbf{F}$

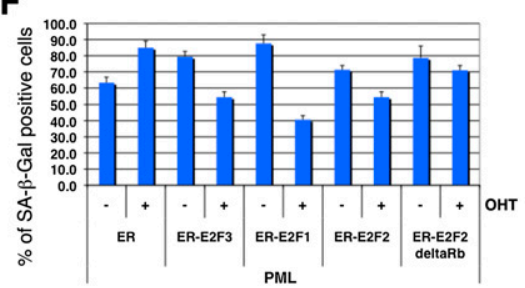

Figure 4. E2F-inhibition is required for PML-induced senescence. $(A, B)$ E7 inhibits $\mathrm{Rb} / \mathrm{E} 2 \mathrm{~F}$ localization in PML bodies. Laserscanning confocal microscopy of cells expressing PML and E7 and stained with both anti-PML and anti-Rb antibodies $(A)$ or with both anti-PML and anti-E2F1 antibodies $(B)$. $(C)$ SA- $\beta$-Gal senescence marker of IMR90 cells expressing PML and the indicated vectors. $(D)$ qPCR for E2F target genes with RNA from cells expressing PML and the indicated vectors. $(E)$ BrdU incorporation in cells expressing PML and the indicated vectors. $(F)$ SA- $\beta$-Gal senescence marker of IMR90 cells expressing PML and the indicated vectors.
PML bodies in U2OS cells expressing PML. As reported before, $\mathrm{Rb}$ was detected in PML immunoprecipitates (Alcalay et al. 1998), and we found E2F3 in the same complex (Fig. 5B). Since U2OS cells are p16INK4adeficient (Park et al. 2002), the data suggest that PMLinduced recruitment of $\mathrm{Rb} / \mathrm{E} 2 \mathrm{Fs}$ is independent of this
CDK inhibitor. Of note, the Rb phosphatase PP1 $\alpha$ (protein phosphatase $1 \alpha$ ) is found in PML bodies in both U2OS cells (Fig. 5C) and IMR90 (Supplemental Fig. S7). These results suggest that PML may protect $\mathrm{Rb}$ from CDKdependent phosphorylation and inactivation by localizing it with a protein phosphatase.

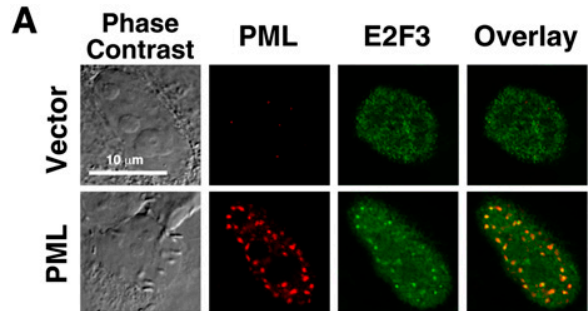

B
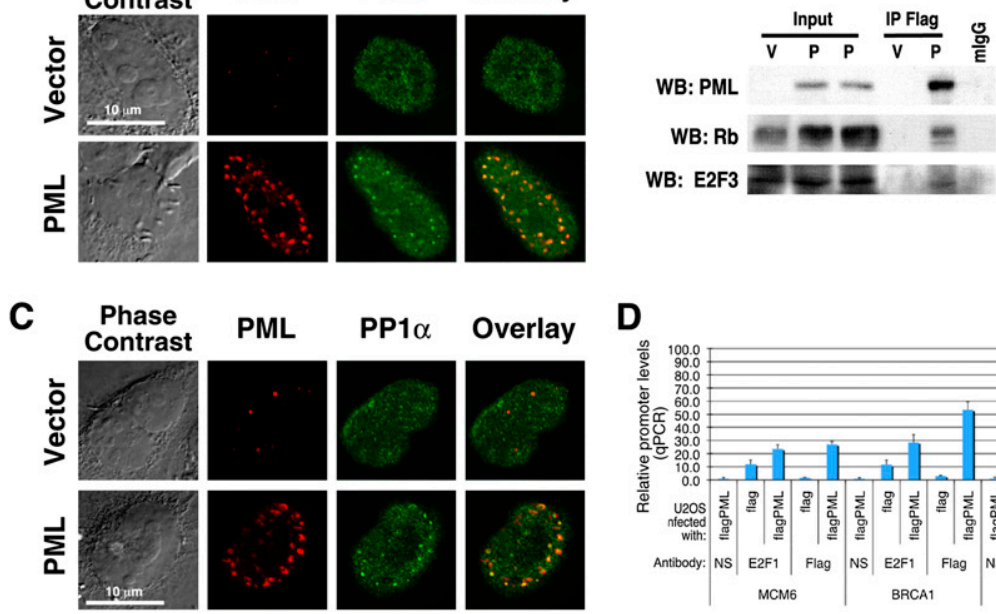

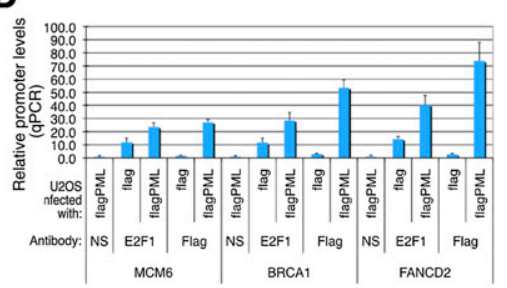

Figure 5. Regulation of E2Fs by PML in $\mathrm{U} 2 \mathrm{OS}$ osteosarcoma cells. (A) Localization of E2F3 in PML bodies in U2OS cells expressing the indicated vectors and stained with antibodies against PML and E2F3. $(B)$ Detection of $\mathrm{PML} / \mathrm{Rb}$ and $\mathrm{PML} / \mathrm{E} 2 \mathrm{~F} 3$ complexes after Flag immunoprecipitation of Flag-PML in U2OS cells expressing FlagPML (P) or a Flag-expressing vector control (V). mIgG is a nonspecific mouse antibody used on Flag-PML extracts. $(C)$ Localization of PP1 $\alpha$ into PML bodies. Cells with the indicated expression vectors were stained with specific antibodies against PML and PP1 $\alpha$. Images were obtained by confocal microscopy. (D) ChIP with anti-E2F1 or anti-Flag antibody in U2OS cells expressing Flag-PML-IV or a Flag-expressing vector (Flag). (NS) Nonspecific normal mouse IgG. 
Next, we investigated whether tethering E2Fs to PML bodies inhibited the DNA-binding activity of E2F transcription factors or, alternatively, whether E2Fs were confined to PML bodies in association with their target promoters. We used ChIP to determine whether E2F1 and PML bind to several E2F target genes in U2OS cells expressing a Flag-PML or a Flag vector control. We found that PML stimulated DNA binding by E2F1, and that PML was associated with all tested E2F target genes (Fig. 5D). This result is consistent with the idea that PML bodies are the sites for nucleation of heterochromatin at E2F target promoters.

\section{PML body formation is defective in prostate tumor cells but is active in benign prostatic hyperplasia (BPH)}

To investigate whether the PML/senescence pathway is important in human cancers, we measured PML expression by immunohistochemistry in tissue microarrays with samples from patients with benign or malignant prostate tumors. $\mathrm{BPH}$ is a benign lesion of the prostate characterized by the presence of senescence markers
(Choi et al. 2000) and low E2F target gene expression (Davis et al. 2006). Of note, in the Oncomine database, we found that multiple E2F target genes are down-regulated in $\mathrm{BPH}$ (Supplemental Fig. S8), including some of the genes found to be down-regulated in PML-induced senescence (Supplemental Fig. S9). We also found a strong staining for the senescence marker p16INK4a in the samples taken from prostates with BPH (Fig. 6A). PML staining in the normal prostate was very weak, but a few PML bodies could be distinguished (Fig. 6B). In contrast, PML staining was stronger in $\mathrm{BPH}$ samples where numerous PML bodies were easily distinguished. On the contrary, PML bodies were rarely distinguished in prostate cancer samples, including prostatic intraepithelial neoplasia (PIN), although we did detect some homogenous expression in the nucleus or cytoplasm (Fig. 6B). To investigate whether the number of PML bodies could distinguish benign lesions from normal or malignant tissues where we occasionally detected PML bodies, we counted the number of PML bodies per cell in prostate samples from different patients. The results clearly indicate that cells from BPH contain more PML bodies than

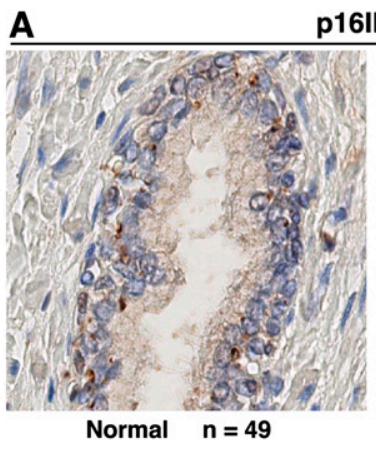

B

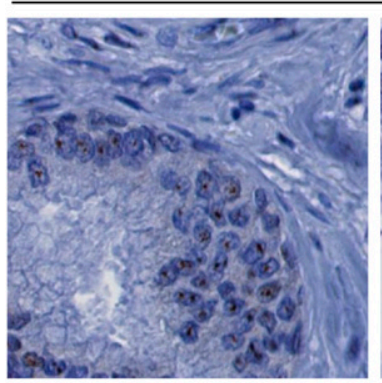

Normal

$26.54 \% \quad n=49$

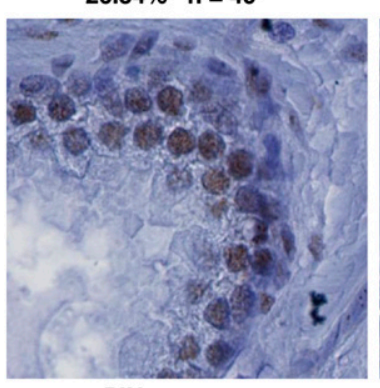

PIN

$0.00 \% \quad n=32$
$16 I N K 4 a$

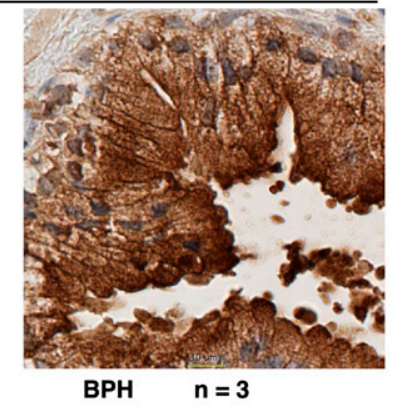

PML

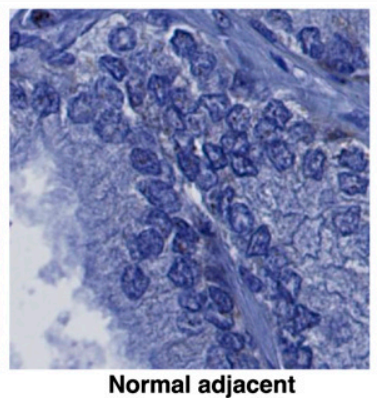

Normal adjacent

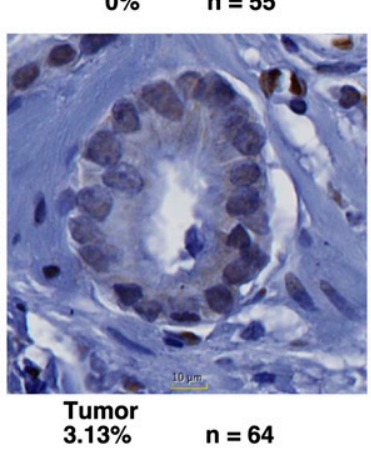

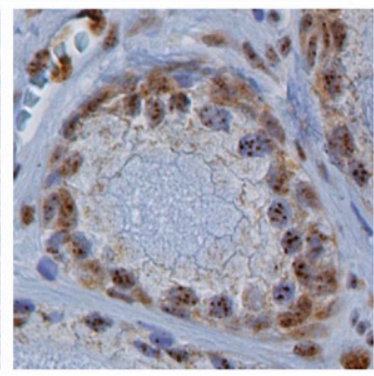

BPH

$100.00 \% \quad n=7$

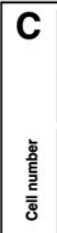

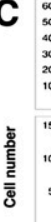

Normal

Illi...

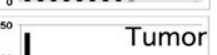

$\left.{ }_{0}\right|_{1 / 1}$

III BPH

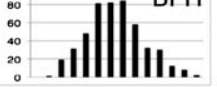

024681012

PML bodies/cell
Figure 6. Expression of PML is increased in $\mathrm{BPH}$ and altered in prostate cancer. (A) Staining for the senescence marker p16INK4a in normal prostates and $\mathrm{BPH}$ samples. (B) PML bodies in normal, benign, and malignant prostate tumors. PML was assessed by staining prostate tissue samples of $\mathrm{BPH}(n=7)$ and tissue microarrays containing cores with normal prostate $\mid n=$ 49), normal prostate adjacent to tumors $(n=55)$, PINs $(n=32)$, and prostate carcinoma $(n=64)$. Percentages indicate nuclei positive for four or more PML bodies. Magnification, 40×. (C) PML bodies were counted in individual epithelial cells from sections of normal prostate (12 patients, 1306 cells), prostate carcinoma (five patients, 340 cells), and BPH (six patients, 489 cells). However, since no PML staining was observed in the normal prostate adjacent to tumors or in PIN lesions, we did not count PML bodies in those samples. In tumors, the counts refer to the few samples where PML bodies were observed. 
cells from normal tissues or cells from the few cases of prostate carcinomas where PML bodies were visualized (Fig. 6C). Taken together, our results suggest that PML bodies may suppress malignant transformation in the prostate by promoting senescence, and that PML staining could be used to distinguish benign from malignant lesions.

\section{Discussion}

Senescence is a permanent cell cycle arrest induced by oncogenes, short telomeres, and some cytokines, preventing the proliferation of cells with malignant potential. The promyelocytic leukemia tumor suppressor PML plays a critical role in senescence, and its activity has been linked to the tumor suppressors p53 and Rb (Bourdeau et al. 2009). PML can induce senescence in cells with disabled p53 (Mallette et al. 2004), indicating that its mechanism of action does not solely involve its direct interaction with this tumor suppressor. Here, we report a novel mechanism by which PML can regulate senescence. PML promotes the localization of $\mathrm{Rb} / \mathrm{E} 2 \mathrm{~F}$ proteins into PML bodies, inhibiting the transcriptional activation function of E2Fs. This mechanism was found not only after enforcing PML expression from a retroviral vector, but also after induction of endogenous PML by $\beta$-interferon, oncogenic ras, or short telomeres.

The inhibition of E2F-dependent gene expression has two important consequences for senescence. First, E2Fs regulate genes required for cell proliferation, explaining why cells expressing PML arrest their proliferation and do not replicate their DNA. Second, many E2F target genes mediate DNA repair and checkpoints, and, in their absence, cells accumulate DNA damage signals that we know are essential for activation of p53 and the senescence process (Bartkova et al. 2006; Di Micco et al. 2006; Mallette et al. 2007). The relationship between PML and p53 is complex. PML and p53 were first linked in the context of PML-induced senescence where p53 was shown to undergo modifications typical of the DNA damage response (Ferbeyre et al. 2000; Pearson et al. 2000).
PML interacts directly with the DNA-binding domain of p53 (Guo et al. 2000) and with the p53 inhibitor MDM2 (Wei et al. 2003). On the other hand, p53 can activate PML gene expression, and pml-null cells are defective in both p53-dependent senescence and apoptosis (de Stanchina et al. 2004). We conclude that these two tumor suppressors are interlinked in positive feedback mechanisms that can be further reinforced by the repression of DNA repair genes and activation of the DNA damage response induced by PML (Fig. 7A).

The localization of $\mathrm{Rb} / \mathrm{E} 2 \mathrm{~F}$ complexes in PML bodies adds another layer of complexity to the classic model of E2F inhibition by the $\mathrm{Rb}$ family. These complexes may better resist the inactivation of $\mathrm{Rb}$ by the CDKs because the relevant CDK phosphorylation sites may be hidden in PML bodies. Alternatively, PML-localized phosphatases may protect the complex from CDK-mediated disruption. Interestingly, one such phosphatase-PP1 $\alpha$ - has an abnormal subcellular distribution in neural progenitor cells from $\mathrm{Pml}^{-/-}$mice that correlates with a dispersed $\mathrm{Rb}$ localization and its hyperphosphorylation (Regad et al. 2009). Normally, $\mathrm{Rb}$ and $\mathrm{PP} 1 \alpha$ are expressed in nuclear granules whose expression partially overlaps with those of each other and PML bodies. By localizing PP1 $\alpha$ with $\mathrm{Rb}$ in PML bodies (Fig. 5C; Supplemental Fig. S7), PML provides a CKI-independent mechanism to activate the $\mathrm{Rb}$ pathway and repress E2F targets during senescence.

Another important implication of our findings concerns the SAHF. It has been shown that PML can help the formation of SAHF (Narita et al. 2003; Zhang et al. 2005), and that several SAHF components localize to PML bodies early in the senescence process. However, once cells are senescent, SAHF and PML bodies are distinct nuclear structures (Supplemental Fig. S3). The details of the dynamic interactions between SAHF components and PML require further study. Nevertheless, our findings suggest that PML bodies recruit E2F target promoters into close proximity to high concentrations of histone deacetylases (HDACs) (Wu et al. 2001), HP1 (Seeler et al. 1998; Zhang et al. 2005), and other heterochromatin factors also in PML bodies. In theory, this concentration effect would
A

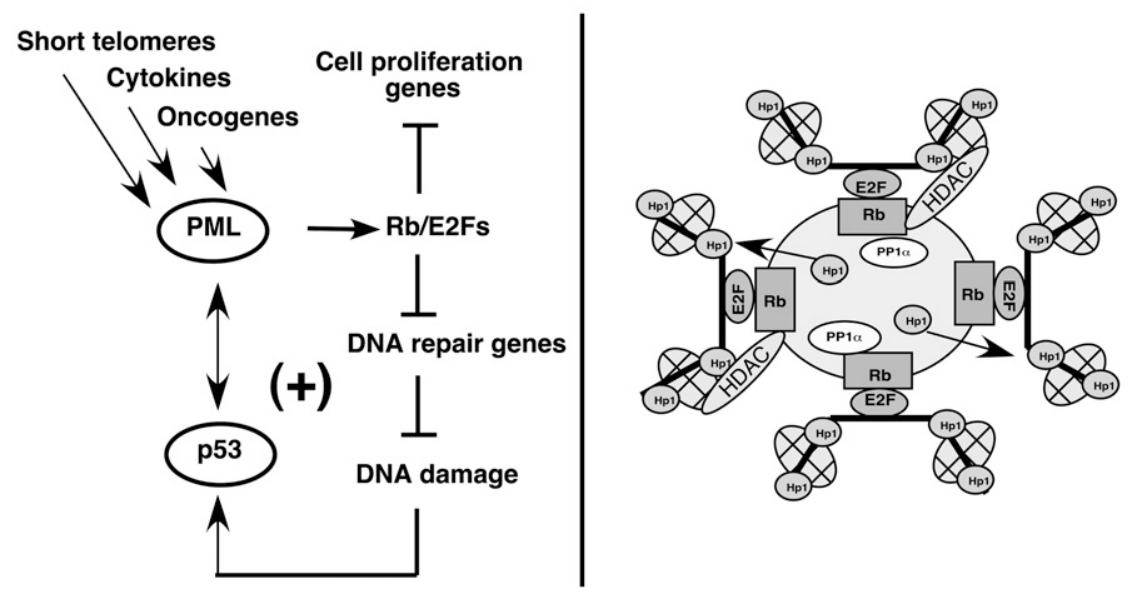

Figure 7. Models of PML functions in senescence. (A) Several positive feedback mechanisms between p53 and PML regulate senescence. In cells expressing PML, the primary effect is the inhibition of E2F target genes, leading to proliferation arrest, DNA damage, and p53 activation, which further activates the PML/Rb/E2F pathway. (B) Schematic view showing a model for a role of PML in E2F target gene repression and formation of heterochromatin foci in senescent cells. Of note, the actual number of E2F promoters per single PML body is unknown. 
allow HP1 proteins to effectively recognize the histone methylation marks catalyzed by $\mathrm{Rb}$-interacting histone methylases (Fig. 7B; Nielsen et al. 2001). Thus, PML bodies could in fact be the site of "nucleation" or initiation of the chromatin condensation on E2F target genes that later become the detectable sites of SAHF.

Finally, the clinical significance of PML-induced senescence was investigated in prostate tumors. In $\mathrm{BPH}$, a benign lesion characterized by the presence of senescence markers (Choi et al. 2000), we found abundant expression of PML and several PML bodies per cell. In multiple samples from normal prostates, we found a moderate PML expression and only two to four PML bodies per cell (Fig. 6C). Prostate cancer patients displayed a varied pattern of PML staining. Areas of negative and positive staining were found in the same tumor, and PML bodies were rarely visualized. This lack of PML bodies in tumor cells can explain why prostate tumors exhibit high levels of expression of E2F target genes such as EZH2 (Stanbrough et al. 2006) and BRCA1 (Schayek et al. 2009; Fiorentino et al. 2010). Interestingly, BRCA1 was one of the genes more efficiently down-regulated in PML-senescent fibroblasts. Given the mechanistic links between PML and the senescence program, the PML status and the number of PML bodies could be used to distinguish malignant from benign tumors in the prostate and, perhaps, other organs.

\section{Materials and methods}

Cells, reagents, and plasmids

U2OS and IMR90 cells were obtained from American Type Culture Collection (ATCC), and were cultured in Dulbecco's modified Eagle medium (DMEM; GIBCO) supplemented with $10 \%$ fetal bovine serum (FBS; Wisent) and $1 \%$ penicillin $\mathrm{G} /$ streptomycin sulfate (GIBCO). Retroviral-mediated gene transfer and BrdU incorporation were done as described previously (Ferbeyre et al. 2000). OHT was from Sigma-Aldrich.

Retroviruses pLPC, pLPC-PML-IV, pWZL, and pWZL-PML-IV were described in Ferbeyre et al. (2000); pBABE-ER-E2Fs were gifts from Dr. K. Helin; and pLXSN-E7, pLXSN-E7 $\Delta 6-10$, pLXSN-E7 $\Delta 21-24$, and pLXSN-E7 $\Delta 79-83$ were gifts from Dr. D. Galloway.

\section{Cell proliferation and senescence determination}

To determine cell proliferation rates, we estimated cell counts at different times after plating using a crystal violet retention assay (Ferbeyre et al. 2000). SA- $\beta$-Gal activity was assayed as described (Ferbeyre et al. 2000). Data were quantified from 100 cell counts in triplicate in at least two independent experiments.

\section{Immunoprecipitation, immunoblotting, and ChIP}

Coimmunoprecipitation, ChIP, and immunoblotting assays were performed as described before (Calabrese et al. 2009). Details can be found in the Supplemental Material.

\section{Fluorescence microscopy}

Cells were plated on coverslips at least $24 \mathrm{~h}$ prior to fixation with $4 \%$ paraformaldehyde in PBS for $10 \mathrm{~min}$ at $4^{\circ} \mathrm{C}$. After washing with PBS, cells were treated as follows: For immunofluorescence involving either the E2F1-3 or Rb antibodies, cells were rinsed with Cytoskeleton buffer (10 mM PIPES at pH 6.8, $100 \mathrm{mM}$ $\mathrm{NaCl}, 300 \mathrm{mM}$ glucose, $3 \mathrm{mM} \mathrm{MgCl}$, $1 \mathrm{mM}$ EGTA, $1.2 \mathrm{mM}$ PMSF) for $10 \mathrm{~min}$, washed with PBS, and permeabilized for $5 \mathrm{~min}$ at $4{ }^{\circ} \mathrm{C}$ with $0.5 \%$ Triton X-100 in Cytoskeleton buffer. Then, cells were washed with $3 \%$ bovine serum albumin (BSA) in PBS (PBS/BSA) and incubated overnight with the following primary antibodies diluted in PBS/BSA: anti-E2F1 (1/50; KH-95, SantaCruz Biotechnology), anti-E2F2 (1/200; C-20, SantaCruz Biotechnology), anti-E2F3 (1/200; C-18, SantaCruz Biotechnology), anti-Rb (1/200; G3245, BD Pharmingen), and anti-PP1 $\alpha$ (1/200; C-19, SantaCruz Biotechnology). For the staining with other antibodies, cells were directly permeabilized with $0.5 \%$ Triton X-100 in PBS/BSA after fixation and were incubated overnight with the following primary antibodies: anti-PML (1:400, PG-M3; SantaCruz Biotechnology), anti-PML rabbit polyclonal (1:400; produced by our laboratory against the peptide comprising amino acids 352-356 of human PML-IV, a region common to all PML isoforms), anti-phopho-ATM ${ }^{\text {Ser1981 }}$ (1/200; \#9298, Cell Signaling), anti-phospho-H2AX (JBW301, 1/200; Upstate Biotechnologies), and anti-HA tag (1/200; 6E2, Cell Signaling).

After primary antibodies, cells were washed three times in PBS/BSA and incubated with the appropriate secondary antibody combination (1/4000, AlexaFluor 488 goat anti-mouse, AlexaFluor 488 goat anti-rabbit, AlexaFluor 568 goat anti-mouse, or AlexaFluor 568 goat anti-rabbit; Molecular Probes-Invitrogen) for $1 \mathrm{~h}$ at room temperature. Finally, cells were rinsed three times with PBS alone and once with PBS containing $300 \mathrm{mM}$ DAPI for $10 \mathrm{~min}$ when needed. Images were captured with an Olympus FV300 confocal laser microscope and were processed with Metamorph.

\section{Immunohistochemistry}

We used samples from seven patients diagnosed with BPH and four different tissue microarrays. The first tissue microarray is comprised of 49 normal prostate specimens from autopsies. The second is comprised of normal tissues adjacent to prostate cancer from 55 patients who underwent radical prostatectomy. The third is comprised of PINs from 32 patients. The fourth one was obtained from 64 patients with prostate cancer. Regions of normal or cancerous epithelial tissue were identified by two pathologists and were subsequently spotted on tissue microarrays (Diallo et al. 2007). Specimens were obtained from consenting patients, and the institutional ethics review committee approved the study. Samples were immunostained with a mouse monoclonal anti-PML antibody (1:300; PG-M3, SantaCruz Biotechnology) or anti-p16 ${ }^{\text {INK4a }}(1: 25$; F12, SantaCruz Biotechnology). Primary antibody detection was done using the LSAB 2 peroxidase system from DAKO, Inc., as described previously (Lessard et al. 2003). Briefly, tissue samples were deparaffinized, rehydrated, and treated with $0.3 \% \mathrm{H}_{2} \mathrm{O}_{2}$ in methanol to eliminate endogenous peroxidase activity. Antigen epitope retrieval was performed by heating for $15 \mathrm{~min}$ at $95^{\circ} \mathrm{C}$ in Tris-EDTA buffer (10 mM Tris Base, $1 \mathrm{mM}$ EDTA solution at $\mathrm{pH}$ 9.0) for PML or $10 \mathrm{mM}$ citrate buffer (pH 6.0) for p16 ${ }^{\mathrm{INK} 4 \mathrm{a}}$. All subsequent steps were done at room temperature. The sections were blocked with a protein-blocking serum-free reagent (DAKO), incubated with primary antibody for $60 \mathrm{~min}$ followed by a 20 -min treatment with the secondary biotinylated antibody (DAKO), and then incubated for $20 \mathrm{~min}$ with streptavidin-peroxidase (DAKO). Reaction products were developed with diaminobenzidine (DAKO) containing $0.3 \% \mathrm{H}_{2} \mathrm{O}_{2}$ as a substrate for peroxidase. Nuclei were counterstained with Harris hematoxylin (SigmaAldrich). 


\section{Acknowledgments}

We thank S.W. Lowe for reagents; F. Badeaux, H. Koumakpayi, and the qPCR platform at IRIC for technical assistance; and M. Narita, E. Querido, and members of the Ferbeyre laboratory for critical comments. This work was funded by a grant from the Canadian Cancer Society to G.F. G.F. is a fellow of the FRSQ, and M.F.G.L. is from the Canadian Institute of Health and Research.

\section{References}

Acosta JC, O'Loghlen A, Banito A, Guijarro MV, Augert A, Raguz S, Fumagalli M, Da Costa M, Brown C, Popov N, et al. 2008. Chemokine signaling via the CXCR2 receptor reinforces senescence. Cell 133: 1006-1018.

Alcalay M, Tomassoni L, Colombo E, Stoldt S, Grignani F, Fagioli M, Szekely L, Helin K, Pelicci PG. 1998. The promyelocytic leukemia gene product (PML) forms stable complexes with the retinoblastoma protein. Mol Cell Biol 18: 1084-1093.

Armata HL, Garlick DS, Sluss HK. 2007. The ataxia telangiectasia-mutated target site Ser18 is required for p53-mediated tumor suppression. Cancer Res 67: 11696-11703.

Bartkova J, Rezaei N, Liontos M, Karakaidos P, Kletsas D, Issaeva N, Vassiliou LV, Kolettas E, Niforou K, Zoumpourlis $\mathrm{VC}$, et al. 2006. Oncogene-induced senescence is part of the tumorigenesis barrier imposed by DNA damage checkpoints. Nature 444: 633-637.

Bischof O, Kirsh O, Pearson M, Itahana K, Pelicci PG, Dejean A. 2002. Deconstructing PML-induced premature senescence. EMBO J 21: 3358-3369.

Bischof O, Nacerddine K, Dejean A. 2005. Human papillomavirus oncoprotein E7 targets the promyelocytic leukemia protein and circumvents cellular senescence via the $\mathrm{Rb}$ and p53 tumor suppressor pathways. Mol Cell Biol 25: 1013-1024.

Bourdeau V, Baudry D, Ferbeyre G. 2009. PML links aberrant cytokine signaling and oncogenic stress to cellular senescence. Front Biosci 14: 475-485.

Braig $M$, Lee S, Loddenkemper C, Rudolph C, Peters AH, Schlegelberger B, Stein H, Dorken B, Jenuwein T, Schmitt CA. 2005. Oncogene-induced senescence as an initial barrier in lymphoma development. Nature 436: 660-665.

Calabrese V, Mallette FA, Deschenes-Simard X, Ramanathan S, Gagnon J, Moores A, Ilangumaran S, Ferbeyre G. 2009. SOCS1 links cytokine signaling to p53 and senescence. Mol Cell 36: 754-767.

Cao L, Li W, Kim S, Brodie SG, Deng CX. 2003. Senescence, aging, and malignant transformation mediated by p53 in mice lacking the Brcal full-length isoform. Genes Dev 17: 201-213.

Chang IY, Jin M, Yoon SP, Youn CK, Yoon Y, Moon SP, Hyun JW, Jun JY, You HJ. 2008. Senescence-dependent MutS $\alpha$ dysfunction attenuates mismatch repair. Mol Cancer Res 6: 978989.

Chen Z, Trotman LC, Shaffer D, Lin HK, Dotan ZA, Niki M, Koutcher JA, Scher HI, Ludwig T, Gerald W, et al. 2005. Crucial role of p53-dependent cellular senescence in suppression of Pten-deficient tumorigenesis. Nature 436: 725-730.

Chicas A, Wang X, Zhang C, McCurrach M, Zhao Z, Mert O, Dickins RA, Narita M, Zhang M, Lowe SW. 2010. Dissecting the unique role of the retinoblastoma tumor suppressor during cellular senescence. Cancer Cell 17: 376-387.

Choi J, Shendrik I, Peacocke M, Peehl D, Buttyan R, Ikeguchi EF, Katz AE, Benson MC. 2000. Expression of senescence-associated $\beta$-galactosidase in enlarged prostates from men with benign prostatic hyperplasia. Urology 56: 160-166.
Davis JN, Wojno KJ, Daignault S, Hofer MD, Kuefer R, Rubin MA, Day ML. 2006. Elevated E2F1 inhibits transcription of the androgen receptor in metastatic hormone-resistant prostate cancer. Cancer Res 66: 11897-11906.

de Stanchina E, Querido E, Narita M, Davuluri RV, Pandolfi PP, Ferbeyre G, Lowe SW. 2004. PML is a direct p53 target that modulates p53 effector functions. Mol Cell 13: 523-535.

Diallo JS, Aldejmah A, Mouhim AF, Peant B, Fahmy MA, Koumakpayi IH, Sircar K, Begin LR, Mes-Masson AM, Saad F. 2007. NOXA and PUMA expression add to clinical markers in predicting biochemical recurrence of prostate cancer patients in a survival tree model. Clin Cancer Res 13: 7044-7052.

Di Micco R, Fumagalli M, Cicalese A, Piccinin S, Gasparini P, Luise C, Schurra C, Garre M, Nuciforo PG, Bensimon A, et al. 2006. Oncogene-induced senescence is a DNA damage response triggered by DNA hyper-replication. Nature 444: 638-642.

Dimri GP, Hara E, Campisi J. 1994. Regulation of two E2Frelated genes in presenescent and senescent human fibroblasts. I Biol Chem 269: 16180-16186.

Dyson N. 1998. The regulation of E2F by pRB-family proteins. Genes Dev 12: 2245-2262.

Essaghir A, Toffalini F, Knoops L, Kallin A, van Helden J, Demoulin JB. 2010. Transcription factor regulation can be accurately predicted from the presence of target gene signatures in microarray gene expression data. Nucleic Acids Res 38: e120. doi: 10.1093/nar/gkq149.

Ferbeyre G, de Stanchina E, Querido E, Baptiste N, Prives C, Lowe SW. 2000. PML is induced by oncogenic ras and promotes premature senescence. Genes Dev 14: 2015-2027.

Fiorentino M, Judson G, Penney K, Flavin R, Stark J, Fiore C, Fall K, Martin N, Ma J, Sinnott J, et al. 2010. Immunohistochemical expression of BRCA1 and lethal prostate cancer. Cancer Res 70: 3136-3139.

Fogal V, Gostissa M, Sandy P, Zacchi P, Sternsdorf T, Jensen K, Pandolfi PP, Will H, Schneider C, Del Sal G. 2000. Regulation of p53 activity in nuclear bodies by a specific PML isoform. EMBO J 19: 6185-6195.

Gotea V, Ovcharenko I. 2008. DiRE: Identifying distant regulatory elements of co-expressed genes. Nucleic Acids Res 36: W133-W139. doi: 10.1093/nar/gkn300.

Guo A, Salomoni P, Luo J, Shih A, Zhong S, Gu W, Paolo Pandolfi P. 2000. The function of PML in p53-dependent apoptosis. Nat Cell Biol 2: 730-736.

Gurrieri C, Capodieci P, Bernardi R, Scaglioni PP, Nafa K, Rush LJ, Verbel DA, Cordon-Cardo C, Pandolfi PP. 2004. Loss of the tumor suppressor PML in human cancers of multiple histologic origins. J Natl Cancer Inst 96: 269-279.

Helt AM, Galloway DA. 2001. Destabilization of the retinoblastoma tumor suppressor by human papillomavirus type 16 E7 is not sufficient to overcome cell cycle arrest in human keratinocytes. J Virol 75: 6737-6747.

Kakizuka A, Miller WHJ, Umesono K, Warrell RPJ, Frankel SR, Murty VV, Dmitrovsky E, Evans RM. 1991. Chromosomal translocation $\mathrm{t}(15 ; 17)$ in human acute promyelocytic leukemia fuses RAR $\alpha$ with a novel putative transcription factor, PML. Cell 66: 663-674.

Lessard L, Mes-Masson AM, Lamarre L, Wall L, Lattouf JB, Saad F. 2003. NF-кB nuclear localization and its prognostic significance in prostate cancer. BJU Int 91: 417-420.

Li W, Ferguson BJ, Khaled WT, Tevendale M, Stingl J, Poli V, Rich T, Salomoni P, Watson CJ. 2009. PML depletion disrupts normal mammary gland development and skews the composition of the mammary luminal cell progenitor pool. Proc Natl Acad Sci 106: 4725-4730. 
Maehara K, Yamakoshi K, Ohtani N, Kubo Y, Takahashi A, Arase S, Jones N, Hara E. 2005. Reduction of total E2F/DP activity induces senescence-like cell cycle arrest in cancer cells lacking functional pRB and p53. J Cell Biol 168: 553560.

Mallette FA, Goumard S, Gaumont-Leclerc MF, Moiseeva O, Ferbeyre G. 2004. Human fibroblasts require the Rb family of tumor suppressors, but not p53, for PML-induced senescence. Oncogene 23: 91-99.

Mallette FA, Gaumont-Leclerc MF, Ferbeyre G. 2007. The DNA damage signaling pathway is a critical mediator of oncogeneinduced senescence. Genes Dev 21: 43-48.

Michaloglou C, Vredeveld LC, Soengas MS, Denoyelle C, Kuilman T, van der Horst CM, Majoor DM, Shay JW, Mooi WJ, Peeper DS. 2005. BRAFE600-associated senescence-like cell cycle arrest of human naevi. Nature 436: 720-724.

Moiseeva O, Bourdeau V, Roux A, Deschenes-Simard X, Ferbeyre G. 2009. Mitochondrial dysfunction contributes to oncogeneinduced senescence. Mol Cell Biol 29: 4495-4507.

Muller H, Bracken AP, Vernell R, Moroni MC, Christians F, Grassilli E, Prosperini E, Vigo E, Oliner JD, Helin K. 2001. E2Fs regulate the expression of genes involved in differentiation, development, proliferation, and apoptosis. Genes Dev 15: $267-285$

Narita M, Nunez S, Heard E, Lin AW, Hearn SA, Spector DL, Hannon GJ, Lowe SW. 2003. Rb-mediated heterochromatin formation and silencing of E2F target genes during cellular senescence. Cell 113: 703-716.

Narita M, Narita M, Krizhanovsky V, Nunez S, Chicas A, Hearn SA, Myers MP, Lowe SW. 2006. A novel role for highmobility group a proteins in cellular senescence and heterochromatin formation. Cell 126: 503-514.

Neri S, Pawelec G, Facchini A, Mariani E. 2007. Microsatellite instability and compromised mismatch repair gene expression during in vitro passaging of monoclonal human $\mathrm{T}$ lymphocytes. Rejuvenation Res 10: 145-156.

Nielsen SJ, Schneider R, Bauer UM, Bannister AJ, Morrison A, $\mathrm{O}^{\prime}$ Carroll D, Firestein R, Cleary M, Jenuwein T, Herrera RE, et al. 2001. Rb targets histone $\mathrm{H} 3$ methylation and HP1 to promoters. Nature 412: 561-565.

Park YB, Park MJ, Kimura K, Shimizu K, Lee SH, Yokota J. 2002. Alterations in the INK4a/ARF locus and their effects on the growth of human osteosarcoma cell lines. Cancer Genet Cytogenet 133: 105-111.

Passos JF, Saretzki G, Ahmed S, Nelson G, Richter T, Peters H, Wappler I, Birket MJ, Harold G, Schaeuble K, et al. 2007. Mitochondrial dysfunction accounts for the stochastic heterogeneity in telomere-dependent senescence. PLOS Biol 5: e110. doi: 10.1371/journal.pbio.0050110.

Pearson M, Carbone R, Sebastiani C, Cioce M, Fagioli M, Saito S, Higashimoto Y, Appella E, Minucci S, Pandolfi PP, et al. 2000. PML regulates p53 acetylation and premature senescence induced by oncogenic Ras. Nature 406: 207-210.

Phelps WC, Munger K, Yee CL, Barnes JA, Howley PM. 1992. Structure-function analysis of the human papillomavirus type 16 E7 oncoprotein. J Virol 66: 2418-2427.

Regad T, Bellodi C, Nicotera P, Salomoni P. 2009. The tumor suppressor Pml regulates cell fate in the developing neocortex. Nat Neurosci 12: 132-140.

Rowland BD, Denissov SG, Douma S, Stunnenberg HG, Bernards R, Peeper DS. 2002. E2F transcriptional repressor complexes are critical downstream targets of p19(ARF)/p53-induced proliferative arrest. Cancer Cell 2: 55-65.

Schayek H, Haugk K, Sun S, True LD, Plymate SR, Werner H. 2009. Tumor suppressor BRCA1 is expressed in prostate cancer and controls insulin-like growth factor I receptor
(IGF-IR) gene transcription in an androgen receptor-dependent manner. Clin Cancer Res 15: 1558-1565.

Seeler JS, Marchio A, Sitterlin D, Transy C, Dejean A. 1998. Interaction of SP100 with HP1 proteins: A link between the promyelocytic leukemia-associated nuclear bodies and the chromatin compartment. Proc Natl Acad Sci 95: 7316-7321.

Smith EJ, Leone G, DeGregori J, Jakoi L, Nevins JR. 1996. The accumulation of an E2F-p130 transcriptional repressor distinguishes a G0 cell state from a G1 cell state. Mol Cell Biol 16: 6965-6976.

Stanbrough M, Bubley GJ, Ross K, Golub TR, Rubin MA, Penning TM, Febbo PG, Balk SP. 2006. Increased expression of genes converting adrenal androgens to testosterone in androgen-independent prostate cancer. Cancer Res 66: 28152825.

Tibbetts RS, Brumbaugh KM, Williams JM, Sarkaria JN, Cliby WA, Shieh SY, Taya Y, Prives C, Abraham RT. 1999. A role for ATR in the DNA damage-induced phosphorylation of p53. Genes Dev 13: 152-157.

Vigo E, Muller H, Prosperini E, Hateboer G, Cartwright P, Moroni MC, Helin K. 1999. CDC25A phosphatase is a target of E2F and is required for efficient E2F-induced S phase. Mol Cell Biol 19: 6379-6395.

Wang ZG, Delva L, Gaboli M, Rivi R, Giorgio M, Cordon-Cardo C, Grosveld F, Pandolfi PP. 1998. Role of PML in cell growth and the retinoic acid pathway. Science 279: 1547-1551.

Wei X, Yu ZK, Ramalingam A, Grossman SR, Yu JH, Bloch DB, Maki CG. 2003. Physical and functional interactions between PML and MDM2. J Biol Chem 278: 29288-29297.

Wu WS, Vallian S, Seto E, Yang WM, Edmondson D, Roth S, Chang KS. 2001. The growth suppressor PML represses transcription by functionally and physically interacting with histone deacetylases. Mol Cell Biol 21: 2259-2268.

Xu X, Bieda M, Jin VX, Rabinovich A, Oberley MJ, Green R, Farnham PJ. 2007. A comprehensive ChIP-chip analysis of E2F1, E2F4, and E2F6 in normal and tumor cells reveals interchangeable roles of E2F family members. Genome Res 17: 1550-1561.

Ye X, Zerlanko B, Zhang R, Somaiah N, Lipinski M, Salomoni P, Adams PD. 2007. Definition of pRB- and p53-dependent and -independent steps in HIRA/ASF1a-mediated formation of senescence-associated heterochromatin foci. Mol Cell Biol 27: 2452-2465.

Zhang R, Poustovoitov MV, Ye X, Santos HA, Chen W, Daganzo SM, Erzberger JP, Serebriiskii IG, Canutescu AA, Dunbrack $\mathrm{RL}$, et al. 2005. Formation of MacroH2A-containing senescence-associated heterochromatin foci and senescence driven by ASF1a and HIRA. Dev Cell 8: 19-30.

Zhang X, Sejas DP, Qiu Y, Williams DA, Pang Q. 2007. Inflammatory ROS promote and cooperate with the Fanconi anemia mutation for hematopoietic senescence. I Cell Sci 120: $1572-1583$. 


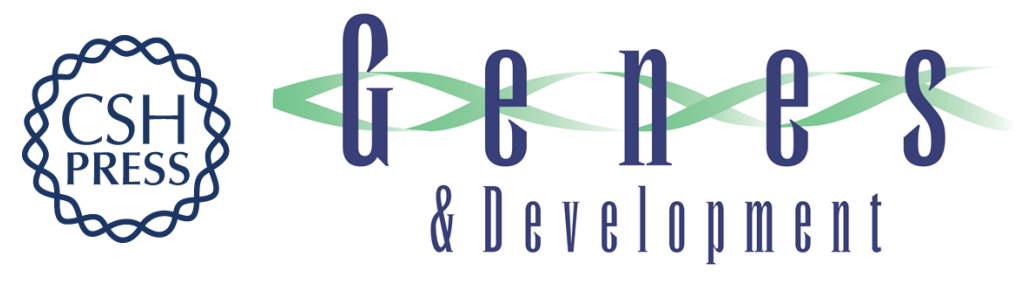

\section{Regulation of E2Fs and senescence by PML nuclear bodies}

Mathieu Vernier, Véronique Bourdeau, Marie-France Gaumont-Leclerc, et al.

Genes Dev. 2011, 25:

Access the most recent version at doi:10.1101/gad.1975111

Supplemental
Material http://genesdev.cshlp.org/content/suppl/2010/12/28/25.1.41.DC1

References This article cites 60 articles, 32 of which can be accessed free at: http://genesdev.cshlp.org/content/25/1/41.full.html\#ref-list-1

License

Email Alerting Receive free email alerts when new articles cite this article - sign up in the box at the top Service right corner of the article or click here.

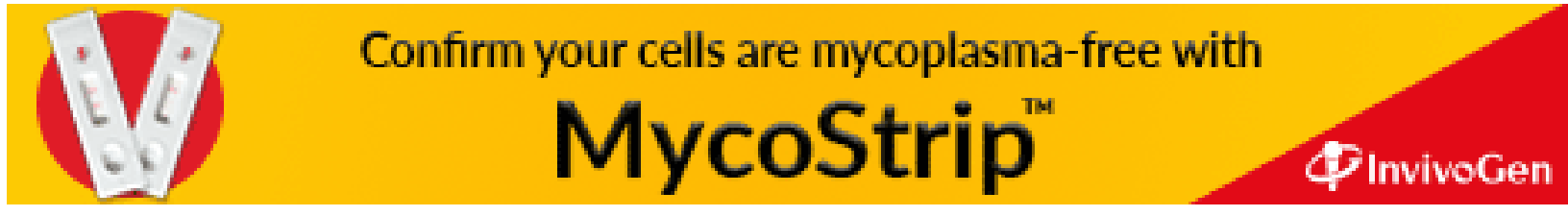

